\title{
Music as a sleep aid in fibromyalgia
}

\author{
Larry M Picard MD FRCPC ${ }^{1,2}$, Lee R Bartel PhD ${ }^{1}$, Allan S Gordon MD FRCPC ${ }^{1,2}$, Davor Cepo BSc DC ${ }^{1}$, \\ Qi Wu MD PhD², Leah R Pink RN MN²
}

LM Picard, LR Bartel, AS Gordon, D Cepo, Q Wu, LR Pink. Music as a sleep aid in fibromyalgia. Pain Res Manag 2014;19(2):97-101.

BACKGROUND: Interventions to improve sleep in fibromyalgia may generalize to improvements in multiple symptom domains. Delta-embedded music, pulsating regularly within the $0.25 \mathrm{~Hz}$ to $4 \mathrm{~Hz}$ frequency band of brain wave activity, has the potential to induce sleep.

OBJECTIVES: To assess the effects of a delta-embedded music program over four weeks for sleep induction in patients with fibromyalgia.

METHODS: The present unblinded, investigator-led pilot study used a within-subject design. Analysis was based on 20 individuals with fibromyalgia who completed the study, of the 24 recruited into the study. The primary outcome variables were the change from baseline in Fibromyalgia Impact Questionnaire (FIQ) and Jenkins Sleep Scale scores. A patient global impression of change was measured on a seven-point Likert scale. Secondary outcome measures, comprised of items 5, 6 and 7 of the FIQ, were used as indicators of pain, tiredness and being tired on awakening.

RESULTS: The FIQ median score of 76.4 (95\% CI 61.3 to 82.1 ) at baseline improved to 60.3 (95\% CI 53.1 to $72.0 ; \mathrm{P}=0.004)$. The Jenkins Sleep Scale median value of 17.5 (95\% CI 15.5 to 18.5 ) at baseline fell to $12.5(95 \%$ CI 8.5 to $14.5 ; \mathrm{P}=0.001)$ at study completion. The outcomes of the patient global impression of change ratings were mostly positive $(\mathrm{P}=0.001)$. Being tired on awakening declined significantly from a median of $9.0(95 \%$ CI 8.0 to 10.0 ) to 8.0 ( $95 \%$ CI 5.5 to $9.0 ; \mathrm{P}=0.021$ ). However, there was no significant improvement in pain level (baseline median 7.5 [95\% CI 7.0 to 8.5 ] versus study completion median 7.0 [95\% CI 6.5 to 8.0]; $\mathrm{P}=0.335$ ) or tiredness (baseline median 9.0 [95\% CI 8.0 to 9.5] versus study completion median 8.0 [95\% CI 6.0 to 8.5 ]; $\mathrm{P}=0.061$ ). There were no serious adverse events.

CONCLUSIONS: Delta-embedded music is a potential alternative therapy for fibromyalgia.

Key Words: Delta embedded music; Fibromyalgia; Sleep disorders

Tibromyalgia is a common chronic pain disorder. In addition to the defining feature of widespread pain, the range of symptoms is wide (1). Common therapeutic approaches include medications, physical therapies, psychologically based therapies and complementary/ alternative modalities (2). Nevertheless, the optimal management of fibromyalgia remains unclear (3).

Morning stiffness, fatigue and nonrestorative sleep were the three most intense symptoms identified in a large Internet survey (2596 respondents). Prescription sleep medications, resting and relaxation/meditation were among the interventions rated as most effective overall for fibromyalgia symptoms (4).

Poor sleep quality is a major feature of fibromyalgia, with $>90 \%$ of fibromyalgia sufferers affected in some studies $(5,6)$. In addition, sleep disturbances influence fatigue levels and social functioning (5), quality of life $(7,8)$ and $\operatorname{mood}(9,10)$.

Sleep is dependent on, and characterized by, an increase in rhythmic oscillatory coherence resulting in a rise in electropotential power in the electroencephalogram delta frequency band $(0.25 \mathrm{~Hz}$ to $4 \mathrm{~Hz})$. A regularly occurring auditory pulse at a frequency of $2 \mathrm{~Hz}$ has been shown to increase stimulus-locked oscillatory coherence at $2 \mathrm{~Hz}$ and

\section{La musique pour favoriser le sommeil en cas de fibromyalgie}

HISTORIQUE : Les interventions pour améliorer le sommeil en cas de fibromyalgie peuvent se généraliser pour susciter des améliorations dans de multiples domaines de symptômes. La musique intégrée dans des cartes Delta, pulsant régulièrement dans la bande de fréquence d'activité des ondes cérébrales de $0,25 \mathrm{~Hz}$ à $4 \mathrm{~Hz}$, a le potentiel d'induire le sommeil.

OBJECTIFS : Évaluer les effets d'un programme de musique intégré dans des cartes Delta pendant quatre semaines pour induire le sommeil chez des patients atteints de fibromyalgie.

MÉTHODOLOGIE : Le présent projet pilote sans insu mené par des chercheurs faisait appel à une méthodologie par sujet. L'analyse reposait sur les 20 patients sur 24 atteints de fibromyalgie recrutés dans l'étude qui l'avaient terminée. Les variables de résultats primaires étaient le changement des indices du questionnaire FIQ sur l'effet de la fibromyalgie et de l'échelle de sommeil de Jenkins par rapport au début de l'étude. Les chercheurs ont mesuré l'impression globale de changement de la part des patients d'après l'échelle de Likert en sept points. Ils se sont servi des mesures de résultats secondaires, composées des questions 5, 6 et 7 du questionnaire FIQ, comme indicateurs de douleur, de fatigue et de lassitude à l'éveil.

RÉSULTATS : L'indice médian du questionnaire FIQ de 76,4 (95 \% IC 61,3 à 82,1) en début d'étude s'améliorait à 60,3 (95\% IC 53,1 à 72,0; $\mathrm{P}=0,004)$. La valeur médiane de l'échelle de sommeil de Jenkins de 17,5 (95\% IC 15,5 à 18,5) en début d'étude régressait à 12,5 (95\% IC $8,5$ à 14,$5 ; \mathrm{P}=0,001)$ en fin d'étude. Les résultats de l'impression globale de changement de la part des patients étaient surtout positifs $(\mathrm{P}=0,001)$. La lassitude à l'éveil diminuait considérablement, passant d'une médiane de $9,0(95 \%$ IC 8,0 à 10,0) à 8,0 (95 \% IC 5,5 à 9,0; P=0,021). Cependant, il n'y avait pas d'amélioration significative du taux de douleur (médiane de 7,5 en début d'étude [95 \% IC 7,0 à 8,5]) par rapport à la fin de l'étude (médiane de 7,0 [95 \% IC 6,5 à 8,0]; $\mathrm{P}=0,335$ ) ou de la fatigue (médiane de 9,0 en début d'étude [95 \% IC 8,0 à 9,5]) par rapport à la fin de l'étude (médiane de 8,0 [95 \% IC 6,0 à 8,5]; P=0,061). Aucun événement indésirable d'importance ne s'est produit.

CONCLUSIONS : La musique intégrée dans des cartes Delta est une thérapie potentielle en cas de fibromyalgie.

boost delta activity (11). Music with an embedded persistent periodic stimulus at $2 \mathrm{~Hz}$ increases delta-band activity and has the potential to decrease sleep onset latency.

Treatment with sodium oxybate, primarily targeted to affect sleep, has been shown to have positive effects on fibromyalgia pain and other symptom domains (12-16). However, nonpharmacological measures could improve sleep quality (17) with fewer potential adverse effects.

A small number of studies have evaluated music in various forms in the treatment of fibromyalgia or chronic widespread pain (18-24). Music had a positive effect on some outcome measures in all of the cited studies, with one exception (20). However, no studies have addressed the use of music as a sleep aid in fibromyalgia.

\section{Participants}

\section{METHODS}

A total of 24 volunteer subjects recruited from the Wasser Pain Management Centre (Toronto, Ontario) provided written informed consent following approval by the Mount Sinai Hospital Research Ethics Board. The trial was conducted in accordance with the principals set out in the Declaration of Helsinki (25). 
TABLE 1

Demographic and clinical characteristics of recruits

\begin{tabular}{lccc}
\hline Characteristic & Completers & Noncompleters & $\mathbf{P}$ \\
\hline Age, years, mean \pm SD & $46.4 \pm 10.6$ & $41.5 \pm 16.6$ & 0.454 \\
Sex, $\mathrm{n}(\%)$ & & & 0.41 \\
$\quad$ Female & $17(85)$ & $4(100)$ & \\
$\quad$ Male & $3(15)$ & $0(0)$ & \\
Duration of FM, years, mean \pm SD & $9.1 \pm 6.9$ & $16.0 \pm 9.8^{*}$ & 0.139 \\
Initial FIQ & & & 0.463 \\
$\quad$ Mean \pm SD & $72.0 \pm 14.4$ & $58.8 \pm 12.4$ & \\
$\quad$ Median & 76.4 & 59.2 & \\
Initial JSS & & & 0.395 \\
$\quad$ Mean \pm SD & $16.4 \pm 3.5$ & $14.8 \pm 2.2$ & \\
$\quad$ Median & 17.5 & 15.0 & \\
\hline
\end{tabular}

${ }^{*}$ Data were available for only three of four noncompleters. FIQ Fibromyalgia Impact Questionnaire (27); FM Fibromyalgia; JSS Jenkins Sleep Scale (28)

TABLE 2

Audio program usage summary

\begin{tabular}{lccc}
\hline & & \multicolumn{2}{c}{ Range } \\
\cline { 3 - 4 } Metric & Mean \pm SD & Minimum & Maximum \\
\hline Exposure days & $31.7 \pm 4.0$ & 21 & 41 \\
Days of use & $24.7 \pm 8.3$ & 6 & 39 \\
Applications & $40.8 \pm 23.1$ & 6 & 92 \\
Applications per treatment day & $1.28 \pm 0.75$ & 0.19 & 2.88 \\
\hline
\end{tabular}

To be eligible, the subjects had to meet recently revised criteria for fibromyalgia (26). Subjects were required to attend both a baseline and a postcompletion data gathering session, read and write English adequately, have satisfactory hearing bilaterally (by self-report) for the appreciation of music and have the ability to operate the supplied listening device. Recruits were subject to exclusion if there was any objection of sleep/bed partner or family members to study participation or if there was a history of a seizure disorder.

No compensation was provided. However, participants were permitted to keep one copy of the supplied music program. Four participants did not attend the final assessment and were not included in the final analysis. None of the recruits were disqualified by the exclusion criteria. Table 1 details the demographic and clinical characteristics of the recruits.

\section{Intervention}

The study was of four weeks' duration. Patients continued to receive usual care, which could vary through the course of the study. Participants were given a music program ('Music to Promote Sleep' on the Sonic Aid label by Somerset Entertainment) on an MP3 player. The program material was chosen specifically for its embedded content of mostly $2 \mathrm{~Hz}$ binaural beats. All participants received the same device and earbuds (Coby MP620-4GBLK, Coby Electronics Corporation, USA).

Subjects were instructed to initiate the audio selection at bedtime and continue at their individual discretion. Program repetition, ad libitum, in the event of awakening was permitted. Playback volume was adjusted to match the participant's comfort level.

In the event of adverse reactions patients were advised to discontinue the intervention and report to one of the investigators.

\section{Assessments and outcome measures}

Demographic data comprising patient age, sex and fibromyalgia duration were collected for descriptive purposes. The Fibromyalgia Impact Questionnaire (FIQ) (27) and Jenkins Sleep Scale (JSS) (28) were administered at study initiation and as close as practicable to the end of week 4 .

A patient global impression of change (GIC-P) was rated on a seven-point Likert scale (ranging from 1 [much worse] to 7 [much better]) at the final assessment.

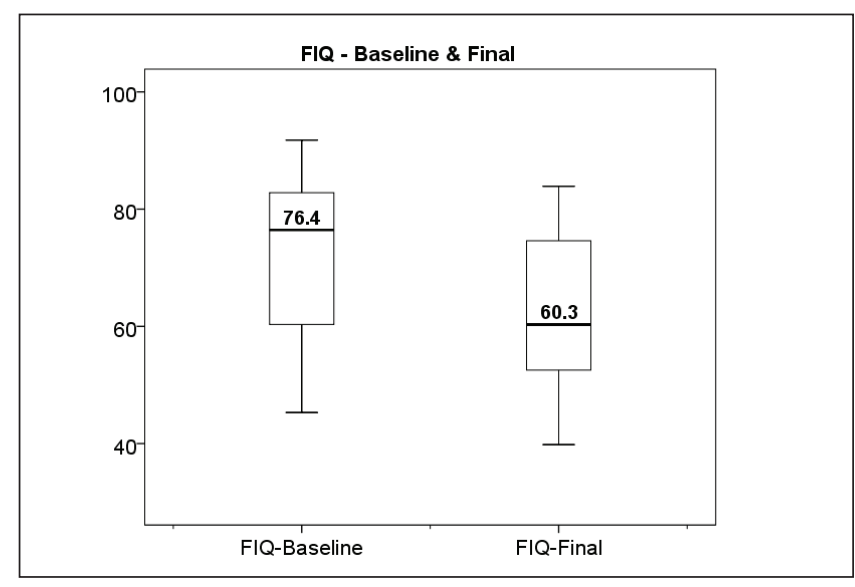

Figure 1) Fibromyalgia Impact Questionnaire (FIQ), baseline and final values (box and whisker plot). Lower scores indicate less severe symptoms

Patients were instructed to complete a compliance calendar tracking the total duration of study ('exposure days'), number of days on which the program was used ('usage days') and total number of applications. The changes from baseline in the FIQ and JSS and GIC-P were the primary end points.

Items 5 ("How bad has your pain been?"), 6 ("How tired have you been?") and 7 ("How have you felt when you get up in the morning?") of the FIQ were used as measures of pain, tiredness and being tired on awakening.

Information about medications and other therapeutic interventions were not systematically collected.

\section{Statistical analysis}

An open within-subject repeated-measures design was used. The demographic and clinical characteristics of completers versus noncompleters were compared using $t$ tests for equality of the means except for the sex ratios, which were compared using the $\chi^{2}$ test.

The Wilcoxon matched pairs test was used to compare baseline and completion values for FIQ, JSS and items 5, 6 and 7 of the FIQ. The Wilcoxon matched pairs test was applied to the GIC-P after imputing a baseline level of 4 (ie, 'no change'). Correlations between selected measures were assessed using Kendal's Tau-b test.

Outcomes were assessed for study completers using SPSS version 21.0.0.0 (IBM Corporation, USA) for Windows (Microsoft Corporation, USA) for data analysis, taking $5 \%$ as the significance threshold. CIs for medians were estimated by bootstrapping.

\section{Principal findings}

\section{RESULTS}

Compliance calendars were completed by 19 patients. Audio program use is summarized in Table 2 .

The FIQ median score of 76.4 (95\% CI 61.3 to 82.1 ) at baseline improved to 60.3 (95\% CI 53.1 to $72.0 ; \mathrm{P}=0.004)$. The JSS median value of $17.5(95 \%$ CI 15.5 to 18.5$)$ at baseline decreased to $12.5(95 \%$ CI 8.5 to $14.5 ; \mathrm{P}=0.001)$ at study completion.

With respect to the GIC-P ratings, one subject reported worsening while five reported no change and 14 reported varying degrees of improvement. Thus, the subjective responses were mostly favourable $(\mathrm{P}=0.001)$. Figures 1 to 3 illustrate the principal findings.

\section{Secondary results}

The pain level, measured on the Likert scale comprising question 5 of the FIQ, was not significantly altered (baseline median 7.5 [95\% CI 7.0 to 8.5$]$ ) compared with the level at study completion (median 7.0 [95\% CI 6.5 to 8.0 ]; $\mathrm{P}=0.335$ ). 


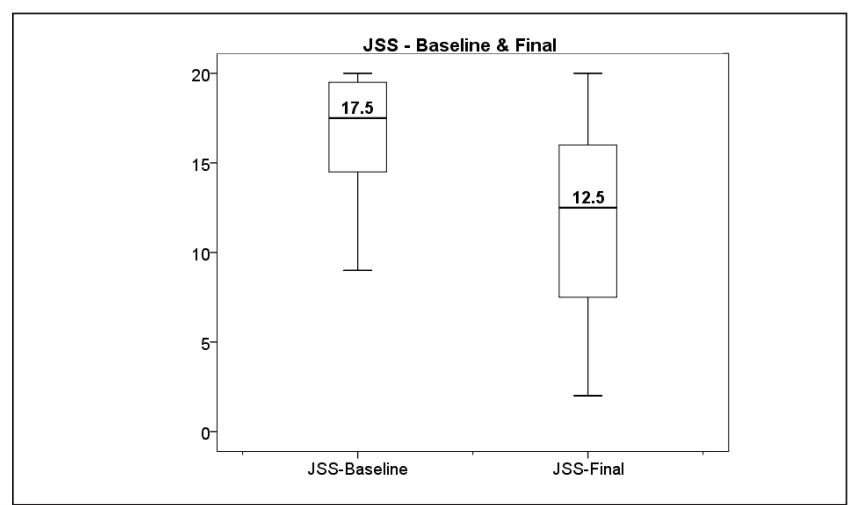

Figure 2) Jenkins Sleep Scale (JSS), baseline and final values (box and whisker plot). Lower scores indicate better sleep quality

TABLE 3

Two-way Kendal Tau-b correlations for selected measures

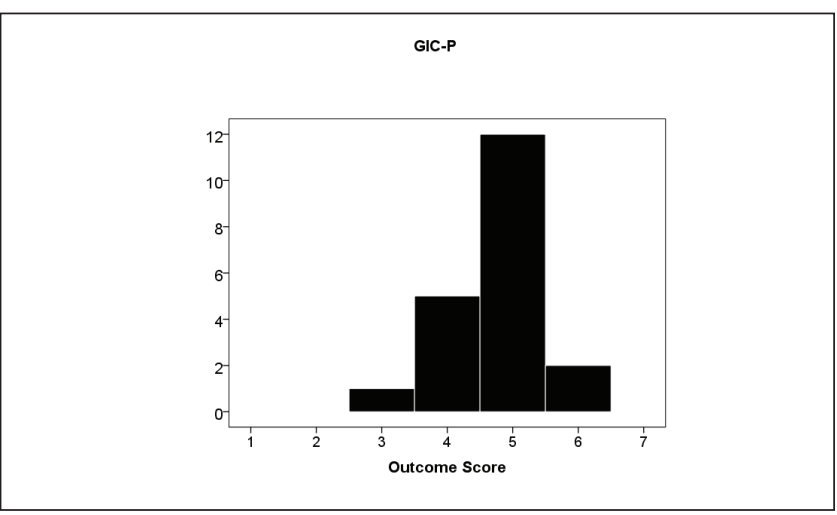

Figure 3) Response counts for patient global impression of change (GIC-P). Scores: 1 = Very much worse; 2 = Much worse; 3 = slightly worse $; 4=$ No change $;=$ Slightly better; $6=$ Much better $7=$ Very much better

\begin{tabular}{|c|c|c|c|c|c|c|c|c|c|c|}
\hline Measure & & Duration $^{\dagger}$ & FIQ-initial ${ }^{\ddagger}$ & FIQ-change $\S$ & $\begin{array}{c}\text { Pain- } \\
\text { change } \pi\end{array}$ & $\begin{array}{c}\text { Tiredness- } \\
\text { change }^{\dagger \dagger}\end{array}$ & $\begin{array}{c}\text { Awakening } \\
\text { tired versus } \\
\text { refreshed- } \\
\text { change }^{\ddagger \ddagger} \\
\end{array}$ & Applications $\$ \S$ & $\begin{array}{c}\text { JSS- } \\
\text { change }{ }^{\pi \pi}\end{array}$ & GIC-P \\
\hline & Significance (2-tailed) & 0.414 & 0.380 & 0.380 & 0.197 & 0.607 & 0.425 & 0.111 & 0.395 & 0.478 \\
\hline \multirow[t]{2}{*}{ Duration $^{\dagger}$} & Correlation coefficient & & -0.323 & 0.097 & 0.152 & -0.073 & -0.035 & 0.032 & -0.227 & -0.119 \\
\hline & Significance (2-tailed) & & 0.050 & 0.557 & 0.394 & 0.680 & 0.841 & 0.845 & 0.178 & 0.525 \\
\hline FIQ-initial $\left.\right|^{\ddagger}$ & Significance (2-tailed) & & & 0.052 & 0.497 & 0.100 & 0.118 & 0.104 & 0.974 & 0.109 \\
\hline \multirow[t]{2}{*}{ FIQ-change $\S$} & Correlation coefficient & & & & $0.370^{*}$ & $0.557^{* *}$ & $0.551^{* *}$ & 0.127 & $0.418^{*}$ & $0.566^{* *}$ \\
\hline & Significance (2-tailed) & & & & 0.035 & 0.001 & 0.001 & 0.436 & 0.012 & 0.002 \\
\hline \multirow[t]{2}{*}{ Pain-change ${ }^{\pi}$} & Correlation coefficient & & & & & 0.121 & 0.270 & 0.270 & 0.215 & -0.317 \\
\hline & Significance (2-tailed) & & & & & 0.520 & 0.145 & 0.126 & 0.232 & 0.111 \\
\hline $\begin{array}{l}\text { Tiredness- } \\
\text { change }^{\dagger \dagger}\end{array}$ & Correlation coefficient & & & & & & $0.448^{*}$ & -0.179 & 0.336 & $0.430^{*}$ \\
\hline \multirow[t]{2}{*}{ Applications $\S \S$} & Correlation coefficient & & & & & & & & $0.387^{*}$ & -0.158 \\
\hline & Significance (2-tailed) & & & & & & & & 0.020 & 0.391 \\
\hline \multirow[t]{2}{*}{ JSS-change } & Correlation coefficient & & & & & & & & & $0.422^{*}$ \\
\hline & Significance (2-tailed) & & & & & & & & & 0.024 \\
\hline
\end{tabular}

Statistically significant correlations are reported in bold. ${ }^{*}$ Correlation is significant at $P<0.05 ;{ }^{* *}$ Correlation is significant at $P<0.01 ;{ }^{\dagger}$ Fibromyalgia duration; ${ }^{\ddagger}$ Baseline FIQ; §Change in Fibromyalgia Impact Questionnaire (FIQ) from baseline; "Change in FIQ item 5 from baseline; ${ }^{+}$Change in FIQ item 6 from baseline; $¥ \neq C h a n g e$ in FIQ item 7 from baseline; $\$ \S$ Number of uses of the music program; ${ }^{\pi T}$ Change in Jenkins Sleep Scale score from baseline; GIC-P Patient global impression of change

Tiredness, as measured by question 6 of the FIQ, declined from a median of 9.0 (95\% CI 8.0 to 9.5 ) to 8.0 (95\% CI 6.0 to 8.5$)$, but this change was not statistically significant $(\mathrm{P}=0.061)$.

Awakening tired versus rested, as measured on the Likert scale comprising question 7 of the FIQ declined significantly from a median of 9.0 (95\% CI 8.0 to 10.0 ) to 8.0 (95\% CI 5.5 to $9.0 ; \mathrm{P}=0.021)$.

Table 3 summarizes the two-way correlations between selected study variables. There were particularly strong correlations between the change in FIQ and changes in tiredness, awakening tired versus refreshed and GIC-P (Kendal's Tau-b correlation coefficients 0.557, 0.551 and $0.556 ; \mathrm{P}=0.001, \mathrm{P}=0.001$ and $\mathrm{P}=0.002$, respectively). Patients averaged $31.7 \pm 4.0$ days on treatment (range 21 to 41 days).

Adverse events

No serious adverse events were reported. Two patients reported discomfort from the earbuds.

\section{DISCUSSION}

The present open-label study evaluated the impact of a tailored music program for sleep induction in individuals with fibromyalgia over a four-week period.

Self-reported, subjective sleep quality, as assessed by the JSS, showed a significant improvement. There were also significant improvements in the FIQ and GIC-P. However, there was no significant effect on pain, possibly reflecting both small effect and small sample sizes. Also, while being tired on awakening improved, there was no effect on overall tiredness.

No serious side effects were reported. Two participants (10\%) reported discomfort from the ear buds. This was not anticipated and, hence, not evaluated systematically. The true numbers may have been higher.

Because of methodological differences, direct comparisons with other studies are not possible. However, the FIQ change from baseline in the 
present study ( -16.1 [a $21 \%$ decline]) compares favourably with that measured in the treatment arms of selected studies of pregabalin ( -5.6 to -16.15) (29-33) and duloxetine (-7.96 to -16.81) (34-38). Furthermore, the magnitude of the intervention effect exceeds 8.1 points or $14 \%$ (ie, the threshold for 'minimal clinically important difference') (39).

In the absence of a control group, and without polysomnography, it is not possible to determine whether delta-embedded music has a quantifiable effect on the sleep patterns of fibromyalgia sufferers. Furthermore, we cannot ascertain whether the program material is optimal or whether better effects could be achieved with traditional lullabies (40) or self-selected music, with or without embedded delta rhythms. No attempt was made to control for medication effects (41). Because this was a pragmatic add-on study to usual care, changes to other treatment during the trial were permitted, in part, for ethical reasons. The results could reflect interactions with other treatment modalities or be influenced by changes in treatment outside the study. Longer studies are necessary to assess durability of effect.

The choice of earbuds was mediated by cost factors and convenience. Earphones, earbuds chosen for comfort, open field listening or the use of wireless devices may influence outcomes.

Further studies using controls are necessary to rule out purely placebo effects or apparent benefit from nonstudy interventions. However, the design of a suitable inactive placebo will be problematic.

There is conflicting evidence about the influence of disturbed sleep on pain. Sleep disturbance may be hyperalgesic $(42,43)$. However, both benzodiazepine $(44,45)$ and nonbenzodiazepine hypnotics (' $Z$ drugs') (46-48) fail to improve the pain of fibromyalgia despite positive effects on sleep.

\section{REFERENCES}

1. Mease P. Fibromyalgia syndrome: Review of clinical presentation, pathogenesis, outcome measures, and treatment. J Rheumatol 2005;75:6-21.

2. Arnold LM. Strategies for managing fibromyalgia. Am J Med 2009;122(12 Suppl):S31-43.

3. Goldenberg DL, Burckhardt C, Crofford L. Management of fibromyalgia syndrome. JAMA 2004;292:2388-95.

4. Bennett RM, Jones J, Turk DC, Russell IJ, Matallana L. An Internet survey of 2,596 people with fibromyalgia. BMC Musculoskelet Disord 2007;8:27.

5. Theadom A, Cropley M, Humphrey KL. Exploring the role of sleep and coping in quality of life in fibromyalgia. J Psychosom Res 2007;62:145-51.

6. Bigatti SM, Hernandez AM, Cronan TA, Rand KL. Sleep disturbances in fibromyalgia syndrome: Relationship to pain and depression. Arthritis Rheum 2008;59:961-7.

7. Wagner JS, Dibonaventura MD, Chandran AB, Cappelleri JC. The association of sleep difficulties with health-related quality of life among patients with fibromyalgia. BMC Musculoskelet Disord 2012;13:199.

8. Consoli G, Marazziti D, Ciapparelli A, et al. The impact of mood, anxiety, and sleep disorders on fibromyalgia. Compr Psychiatry 2012;53:962-7.

9. Haythornthwaite JA, Hegel MT, Kerns RD. Development of a sleep diary for chronic pain patients. J Pain Symptom Manage 1991;6:65-72.

10. Wells RD, Day RC, Carney RM, Freedland KE, Duntley SP. Depression predicts self-reported sleep quality in patients with obstructive sleep apnea. Psychosom Med 2004;66:692-7.

11. Will U, Makeig S. EEG research methodology and brainwave entrainment. In: Berger J, Turow G, eds. Music, Science, and the Rhythmic Brain: Cultural and Clinical Implications. New York: Routledge, 2011:86-110.

12. Scharf MB, Hauck M, Stover R, McDannold M, Berkowitz D. Effect of gamma hydroxybutyrate on pain, sleep, fatigue, and the alpha sleep anomaly in patients with fibromyalgia. Preliminary report. J Rheumatol 1998;25:1986-90.

13. Scharf MB, Baumann M, Berkowitz DV. The effects of sodium oxybate on clinical symptoms and sleep patterns in patients with fibromyalgia. J Rheumatol 2003;30:1070-4.

14. Russell IJ, Perkins AT, Michalek JE. Oxybate SXB-26 Fibromyalgia Syndrome Study Group. Sodium oxybate relieves pain and improves function in fibromyalgia syndrome: A randomized, double-blind,
Deficient inhibitory pain modulation may play a role in fibromyalgia (49). Sleep quality, in turn, influences pain inhibition (50). Nevertheless, our findings suggest that improving sleep quality does not reduce the clinical pain of fibromyalgia. Our results are at variance with the findings of others (51) and may simply reflect inadequate statistical power to demonstrate a small effect. However, sleep quality may not be closely linked to pain intensity in fibromyalgia (52).

\section{CONCLUSION}

The present open-label pilot study supports a potential benefit of delta-embedded music in the treatment of fibromyalgia and fibromyalgia-associated sleep disturbances. The treatment appears to be safe and well tolerated.

Further research is needed to rule out a purely placebo effect, optimize the audio program, determine the best means of program delivery and integrate this potential therapy with other modalities, as well as assess the durability of the effect.

SPONSOR: Jesse \& Julie Rasch Foundation, Toronto, Ontario.

DISCLOSURES: Dr Lee Bartel serves as a paid consultant for the scientific design of music recordings to Mood (formerly Somerset) Entertainment including Fisher Price recordings for children, the Solitudes 'Music for Your Health' series and the Sonic Aid series. He is not a composer or performer on these recordings. He receives no royalties for the Music for Your Health series. He receives limited (noncomposer or performer) royalties for Fisher Price recordings and the Sonic Aid series.

placebo-controlled, multicenter clinical trial. Arthritis Rheum 2009;60:299-309.

15. Moldofsky H, Inhaber NH, Guinta DR, Alvarez-Horine SB. Effects of sodium oxybate on sleep physiology and sleep/wake-related symptoms in patients with fibromyalgia syndrome: A double-blind, randomized, placebo-controlled study. J Rheumatol 2010;37:2156-66.

16. Russell IJ, Holman AJ, Swick TJ, Alvarez-Horine S, Wang YG, Guinta D; Sodium Oxybate 06-008 FM Study Group. Sodium oxybate reduces pain, fatigue, and sleep disturbance and improves functionality in fibromyalgia: Results from a 14-week, randomized, double-blind, placebo-controlled study. Pain 2011;152:1007-17.

17. Edinger JD, Wohlgemuth WK, Krystal AD, Rice JR. Behavioral insomnia therapy for fibromyalgia patients: A randomized clinical trial. Arch Intern Med 2005;165:2527-35.

18. Müller-Busch HC, Hoffmann P. Aktive Musiktherapie bei chronischen Schmerzen: Eine prospektive Untersuchung. Schmerz 1997;11:91-100.

19. Chesky KS, Russell IJ, Lopez Y, Kondraske GV. Fibromyalgia tender point pain: A double-blind, placebo-controlled pilot study of music vibration using the music vibration table. J Musculoskeletal Pain 1997;5:33-52.

20. El Rakshy M, Weston C. An investigation into the possible additive effects of acupuncture and autogenic relaxation in the management of chronic pain. Acupuncture Med 1997;15:74-5.

21. Le Roux F. Music: A new integrated model in physiotherapy. S Afr J Physiother 1998;54:2-11.

22. Schorr JA. Music and pattern change in chronic pain. ANS Adv Nurs Sci 1993;15:27-36.

23. McCaffrey R, Freeman E. Effect of music on chronic osteoarthritis pain in older people. J Adv Nurs 2003;44:517-24.

24. Leão ER, da Silva MJ. Música e dor crônica músculoesquelética: O potencial evocativo de imagens mentais. Rev Lat Am Enfermagem 2004;12:235-41.

25. World Medical Association. Ethics Unit. Declaration of Helsinki 2008. <www.wma.net/en/30publications/10policies/b3/17c.pdf> (Accessed March 1, 2011).

26. Wolfe F, Clauw DJ, Fitzcharles MA, et al. The American College of Rheumatology preliminary diagnostic criteria for fibromyalgia and measurement of symptom severity. Arthritis Care Res (Hoboken) 2010;62:600-10.

27. Bennett R. The Fibromyalgia Impact Questionnaire (FIQ): A review of its development, current version, operating characteristics and uses. Clin Exp Rheumatol 2005;23(5 Suppl 39):S154-62. 
28. Jenkins CD, Stanton BA, Niemcryk SJ, Rose RM. A scale for the estimation of sleep problems in clinical research. J Clin Epidemiol 1988;41:313-21.

29. Ohta H, Oka H, Usui C, Ohkura M, Suzuki M, Nishioka K. An open-label long-term phase III extension trial to evaluate the safety and efficacy of pregabalin in Japanese patients with fibromyalgia. Mod Rheumatol 2013;23:1108-15.

30. Ohta H, Oka H, Usui C, et al. A randomized, double-blind, multicenter, placebo-controlled phase III trial to evaluate the efficacy and safety of pregabalin in Japanese patients with fibromyalgia. Arthritis Res Ther 2012;14:R217.

31. Pauer L, Winkelmann A, Arsenault P et al. A0081100 Investigators. An international, randomized, double-blind, placebocontrolled, phase III trial of pregabalin monotherapy in treatment of patients with fibromyalgia. J Rheumatol 2011;38:2643-52.

32. Arnold LM, Russell IJ, Diri EW et al. A 14-week, randomized, double-blinded, placebo-controlled monotherapy trial of pregabalin in patients with fibromyalgia. J Pain 2008;9:792-805.

33. Mease PJ, Russell IJ, Arnold LM, et al. A randomized, double-blind, placebo-controlled, phase III trial of pregabalin in the treatment of patients with fibromyalgia. J Rheumatol 2008;35:502-14.

34. Chappell AS, Bradley LA, Wiltse C, et al. A six-month doubleblind, placebo-controlled, randomized clinical trial of duloxetine for the treatment of fibromyalgia. Int J Gen Med 2008;1:91-102.

35. Arnold LM, Lu Y, Crofford LJ, et al. A double-blind, multicenter trial comparing duloxetine with placebo in the treatment of fibromyalgia patients with or without major depressive disorder. Arthritis Rheum 2004;50:2974-84.

36. Arnold LM, Zhang S, Pangallo BA. Efficacy and safety of duloxetine $30 \mathrm{mg} / \mathrm{d}$ in patients with fibromyalgia: A randomized, double-blind, placebo-controlled study. Clin J Pain 2012;28:775-81.

37. Chappell AS, Littlejohn G, Kajdasz DK, et al. A 1-year safety and efficacy study of duloxetine in patients with fibromyalgia. Clin J Pain 2009;25:365-75.

38. Arnold LM, Rosen A, Pritchett YL, et al. A randomized, doubleblind, placebo-controlled trial of duloxetine in the treatment of women with fibromyalgia with or without major depressive disorder. Pain 2005;119:5-15.

39. Bennett RM, Bushmakin AG, Cappelleri JC, Zlateva G, Sadosky AB. Minimal clinically important difference in the fibromyalgia impact questionnaire. J Rheumatol 2009;36:1304-11.

40. Reinhardt U. [Investigations into synchronisation of heart rate and musical rhythm in a relaxation therapy in patients with cancer pain]. Forsch Komplementarmed 1999;6:135-41.
41. Roizenblatt S, Neto NS, Tufik S. Sleep disorders and fibromyalgia. Curr Pain Headache Rep 2011;15:347-57.

42. Moldofsky H, Scarisbrick P, England R, Smythe H. Musculosketal symptoms and non-REM sleep disturbance in patients with "fibrositis syndrome" and healthy subjects. Psychosom Med 1975;37:341-51.

43. Moldofsky H, Scarisbrick P. Induction of neurasthenic musculoskeletal pain syndrome by selective sleep stage deprivation. Psychosom Med 1976;38:35-44.

44. Russell IJ, Fletcher EM, Michalek JE, McBroom PC, Hester GG. Treatment of primary fibrositis/fibromyalgia syndrome with ibuprofen and alprazolam. A double-blind, placebo-controlled study. Arthritis Rheum 1991;34:552-60.

45. Quijada-Carrera J, Valenzuela-Castaño A, Povedano-Gómez J, et al. Comparison of tenoxicam and bromazepan in the treatment of fibromyalgia: A randomized, double-blind, placebo-controlled trial. Pain 1996;65:221-5.

46. Drewes AM, Andreasen A, Jennum P, Nielsen KD. Zopiclone in the treatment of sleep abnormalities in fibromyalgia. Scand J Rheumatol 1991;20:288-93.

47. Grönblad M, Nykänen J, Konttinen Y, Järvinen E, Helve T. Effect of zopiclone on sleep quality, morning stiffness, widespread tenderness and pain and general discomfort in primary fibromyalgia patients. A double-blind randomized trial. Clin Rheumatol 1993;12:186-91.

48. Moldofsky H, Lue FA, Mously C, Roth-Schechter B, Reynolds WJ. The effect of zolpidem in patients with fibromyalgia: A dose ranging, double blind, placebo controlled, modified crossover study. J Rheumatol 1996;23:529-33.

49. Julien N, Goffaux P, Arsenault P, Marchand S. Widespread pain in fibromyalgia is related to a deficit of endogenous pain inhibition. Pain 2005;114:295-302.

50. Paul-Savoie E, Marchand S, Morin M, et al. Is the deficit in pain inhibition in fibromyalgia influenced by sleep impairments? Open Rheumatol J 2012;6:296-302.

51. Orlandi AC, Ventura C, Gallinaro AL, Costa RA, Lage LV. Improvement in pain, fatigue, and subjective sleep quality through sleep hygiene tips in patients with fibromyalgia. Rev Bras Reumatol 2012;52:672-8.

52. Anderson RJ, McCrae CS, Staud R, et al. Predictors of clinical pain in fibromyalgia: Examining the role of sleep. J Pain 2012;13:350-8. 


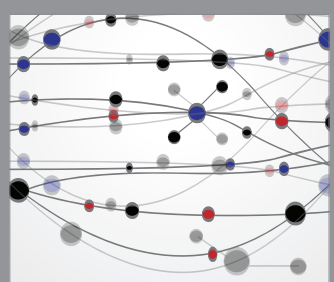

The Scientific World Journal
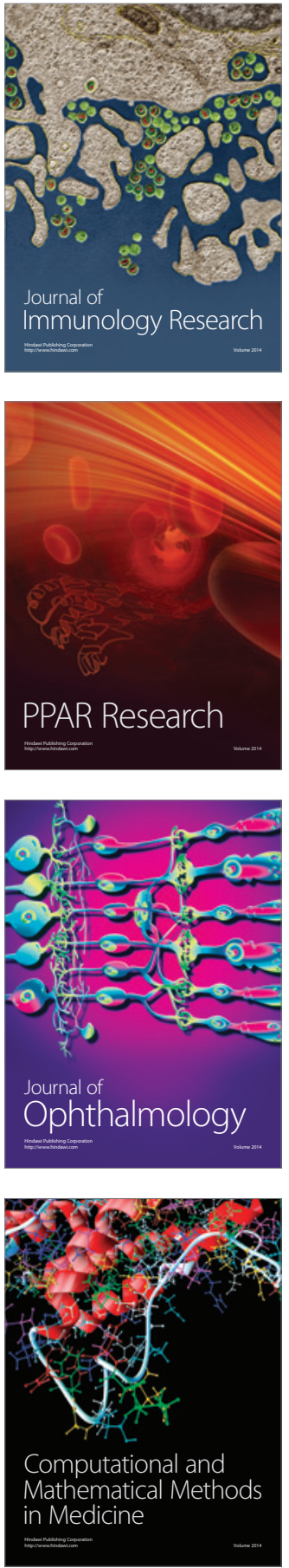

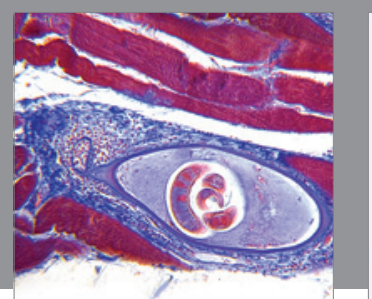

Gastroenterology Research and Practice

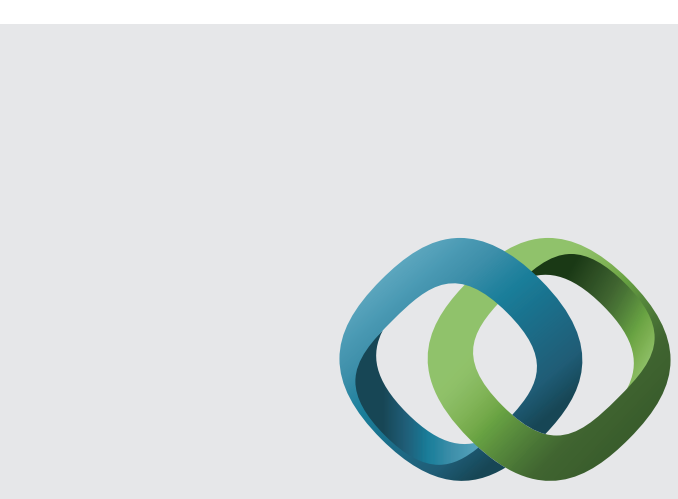

\section{Hindawi}

Submit your manuscripts at

http://www.hindawi.com
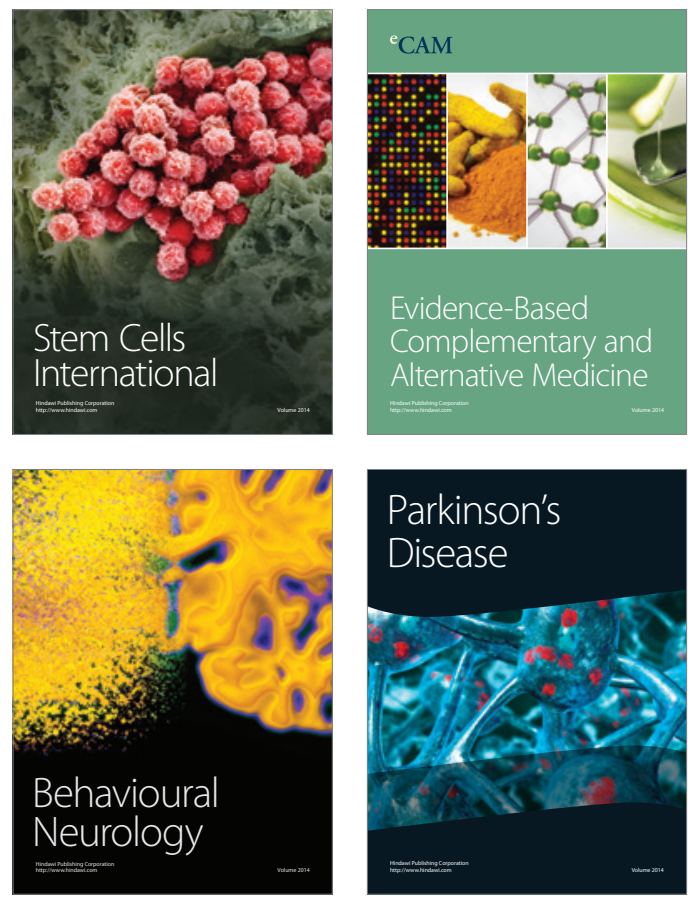
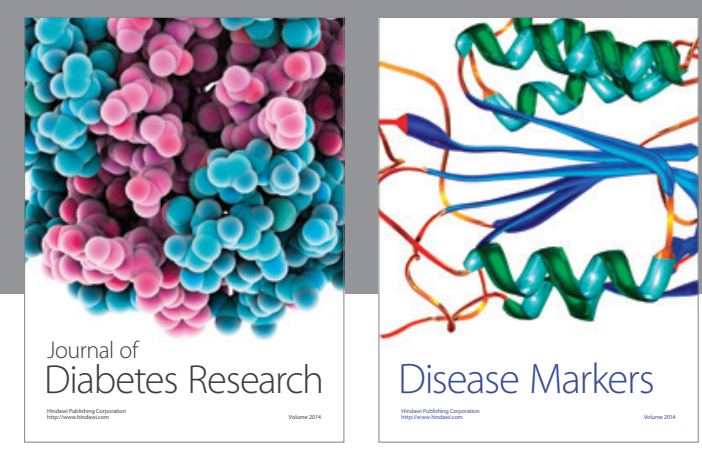

Disease Markers
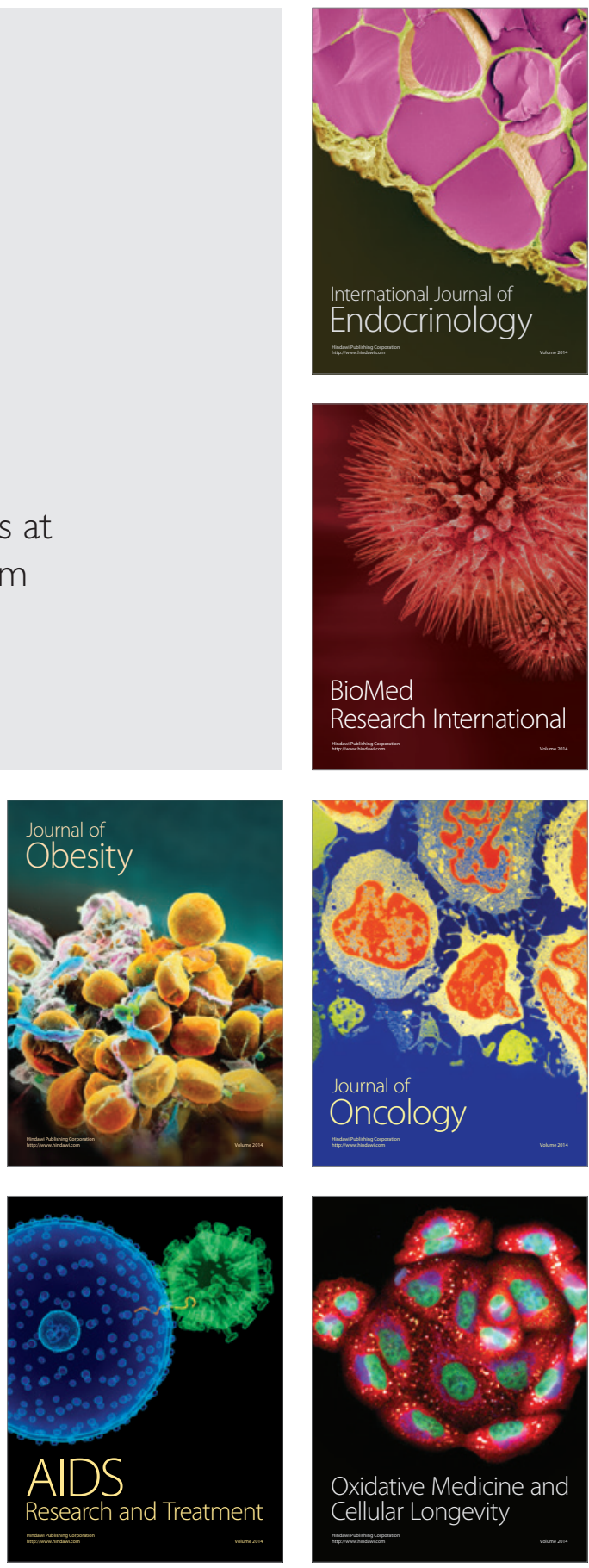